\title{
Human and animal anthrax in Ethiopia: A retrospective record review $2009-2013$
}

\author{
Getahun Bahiru ${ }^{1,3^{*}}$, Abyot Bekele ${ }^{2}$, Bewket Seraw ${ }^{3}$, Lucy Boulanger ${ }^{4}$ and Ahmed Ali ${ }^{5}$ \\ ${ }^{1}$ Federal Democratic Republic of Ethiopian Minstery of livestock and Fisheries Development, \\ Field Epidemiology and Training Program P. O. Box 1047, Addis Ababa, Ethiopia \\ ${ }^{2}$ Ethiopian Public Health Institute, \\ ${ }^{3}$ Federal Democratic Republic of Ethiopian, Ministry of Agriculture, P.O. Box 62347, Addis \\ Ababa, Ethiopia \\ ${ }^{4}$ The Center for Disease Control and Prevention, P. O. Box 1014, Addis Ababa, Ethiopia \\ ${ }^{5}$ Collage of Health Science School of Public Health, Addis Ababa University, P. O. Box 9086, Ad- \\ dis Ababa, Ethiopia \\ ${ }^{*}$ Corresponding author: Ethiopian Minstery of livestock and Fisheries Development, Field Epide- \\ miology and Training Program P.O.Box 1047, Addis Ababa, Ethiopia, Email:gemb2372@gmail. \\ com \\ http://dx.doi.org/10.4314/evj.v20i2.6
}

\begin{abstract}
Globally, 10,000-100,000 human anthrax incidences occur annually with significant number of cases from Chad, Ethiopia, Zambia, Zimbabwe and India. Even though anthrax is a reportable disease in Ethiopia, data have not been analyzed and interpreted for public health intervention. During the past five years, 2009-2013, human and animal anthrax surveillance data were officially requested and received from the Ethiopian Public Health Institute and the Ministry of Agriculture respectively (Reference). The data were analyzed by time and place using micro soft Excel and Epi- info 7.3.1. A total of 5,197 human and 26,737 animal anthrax cases (human to animal ratio 1:5) were reported from 2009 to 2013 with 86 human anthrax deaths (Case Fatality Rate:1.7\%). The National human prevalence was found to be 1.3 per 100,000 populations per five years, while it was 6.7, 2.3, 1.5 and 0.2 in Tigray, Amhara, SNNP and Oromia regions respectively. Zero human case was reported from pastoralist regions with 55-216 animal cases (Afar, Somali and Benshangul Gumuz). The human prevalence was high in May followed by February (0.20 and 0.15 per 100,000 populations per year respectively) This data analysis revealed that less number of human anthrax cases were reported than animal cases (ratio 1:5) in Ethiopia. The pastoralist areas where humans and animals co-exist closely did not report a single human case for the last five years. To determine the magnitude of anthrax in Ethiopia both human
\end{abstract}


and animal surveillance system should be strengthened giving due attention to pastoralist areas. Prevention intervention should be in place in areas where the prevalence of the disease is high.

Keywords: Animal, Anthrax, Ethiopia, Human, Surveillance.

\section{Introduction}

Anthrax is an acute disease of warm blooded animals including human beings caused by a spore forming gram-positive, non-motile bacillus anthracis (Aiello, 1998). The name of the bacterium is derived from "anthrakis", the Greek word for coal, because anthrax in humans causes black, coal-like lesions on the skin at the site of inoculation (Inglesby et al., 1999).

Herbivorous and wild mammals are most commonly infected by anthrax through ingestion or inhalation of spores while grazing. Ingestion is thought to be the most common route by which herbivores contract anthrax. Carnivores living in the same environment may become infected by consuming infected animals (Hudson, 2006). Human cases usually develop after exposure to infected animals and their tissues. In most countries, human anthrax occurs infrequently and sporadically, mainly as an occupational hazard among veterinarians, agricultural workers and workers who process hides, hair, wool and bone products (Lowa State University, 2007)). Human-to-human transmission has not been documented. In humans, cutaneous, gastrointestinal and inhalational are the three forms of anthrax. The incubation period in humans is usually 1 to 7 days, but varies with the form of the disease (WHO, 2008).

Anthrax is globally distributed disease, reported from all continents that are populated heavily with animals and humans. Animal anthrax outbreaks have been recorded in nearly 200 countries by The World Anthrax Data Site, a World Health Organization Collaborating Center for Remote Sensing and Geographic Information Systems for Public Health in 1996-1997 (Hugh Jones, 2001). The data types recorded by The World Anthrax Data Site are: country-oforigin, anthrax status, vaccination program, species affected, year of outbreak, number of outbreaks during the year, number of cases, number vaccinated and total livestock population. The anthrax status of a given country may be classified into one of the six categories: hyper endemic/epidemic, endemic, sporadic, probably free, free and unknown. The countries with hyper endemic/ 
epidemic status are frequently in Africa, like Zimbabwe, from 1978-1980; where there was an epidemic of anthrax causing infection of nearly 10,000 humans and 151 deaths. Examples of regions with unknown anthrax status are the polar extremes, the Arctic and the Antarctic (Noah et al., 1998; Inglesby et al., 2002).

Animal anthrax is an endemic disease in Ethiopia which occurs in May and June every year (anthrax season) in several farming localities of the country, although suspected cases of livestock anthrax are reported from several districts, few of those are officially confirmed (Girum Shiferaw, 2004). The previous studies indicate that the disease is well recognized by rural communities but little is known about its prevalence, epidemiology and public health significance (Teshale Seboxa et al., 1989; Esser et al., 2003). In the Ethiopian fiscal year 2003, according to the Fedral Democratic Republic of Ethiopia Ministry of Health surveillance data, a total of 1,096 suspected human anthrax cases and 16 deaths with a Case Fatality Rate (CFR) of 1.5\% were reported from four regions (Tigray, Amhara, Oromia, and SNNPR). The highest number of cases were reported from Tigray (396), followed by SNNPR (340), Amhara (296), and Oromia (64), while the highest number of deaths (9) were reported in SNNPR (56\% of the total deaths), with Oromia accounting for 5 deaths (31\%) and Tigray for 2 (13\%), (Ministry of Health, 2010/11). In 1993 there were 305 cases reported and none in 1994 (Ministry of Health, 2000; Ministry of Health, 2001a; Ministry of Health, 2001b; Ministry of Health, 2004), which indicating inefficiency and recently developing of the surveillance systems but surveillance data of anthrax is not yet analyzed and communicated to concerned bodies regularly. So, the main propose of this analysis was to assess the five years anthrax trend in order to get valuable inputs and recommend evidence based interventions.

Zoonoses are diseases transmissible between animals (domestic and wildlife) and humans. It has been estimated that $60 \%$ of all human diseases and around $75 \%$ of emerging infectious diseases are zoonotic among which Anthrax is a serious disease that can affect most mammals and several species of birds (Taylor, 2001). In Ethiopia, anthrax is endemic so it is an important public health issue and there is an apparent need for accurate information through a strong surveillance system to warrant evidence based action. Analysis of anthrax data can generate information on the trend of anthrax in Ethiopia and determine the distribution of cases. This helps to identify areas of hyperen demnicity and figure out the 
completeness of the reporting system to engage in corrective actions as well as to implement appropriate control strategy.

According to Public Health Emergency Management Guideline, a suspected case of human anthrax was when any person shows an acute onset of the disease characterized by several clinical forms which include:

\section{1) Localized form}

Cutaneous: skin lesion evolving over 1 to 6 days from a papular through a vesicular stage, to a depressed black Escher invariably accompanied by edema that may be mild to extensive.

\section{2) Systemic forms}

Gastro-intestinal: Abdominal distress characterized by nausea, vomiting, anorexia and followed by fever

Pulmonary (inhalation): brief prodrome resembling acute viral respiratory illness, followed by rapid onset of hypoxia, dyspnea and high temperature, with $\mathrm{x}$-ray evidence of mediastinal widening

Meningeal: acute onset of high fever possibly with convulsions, loss of consciousness, Meningeal signs and symptoms; commonly noted in all systemic infections and has an epidemiological link to confirmed or suspected animal cases or contaminated animal products.

\section{Materials and Methods}

\section{Study area, population and period}

Ethiopia is found in Eastern Africa, between 3 and 15-degree North latitude and 33 and 48-degree East longitude. Djibouti, Eritrea, the Republic of the Sudan, and the Republic of the Southern Sudan, Kenya, and Somalia border the country with a total area of $1,104,300 \mathrm{sq} \mathrm{km}$. Ethiopia is the second most populous country in sub-Saharan Africa after Nigeria, with estimated population of 90 million in July 2011. Five year anthrax data were analyzed (January 27- February 21/2014). 


\section{Source of data}

Secondary data from Ethiopian Public Health Institute/Public Health Emergency Management (EPHI/PHEM) data base from 2009-2013 were used to review human anthrax and animal anthrax data were abstracted from the Ministry Of Agriculture. And human population was obtained from Ethiopian Central Statistics Agency, 2007 census projection.

\section{Study design}

Descriptive method of study was carried out. The trend and distributions of anthrax cases by place and time was presented using graphs, tables. Number of human anthrax cases over five years period of time divided by Five years average or mid- interval human population and multiplied by 100,000 was used to calculate human anthrax prevalence.

\section{Statistical analysis}

Descriptive statistical analysis were made using Epi. Info 7.3.1 and Microsoft Excel

\section{Results}

A total of 5197 and 26737 cases and 86 and 8523 deaths of human and animal anthrax respectively were documented the last five years (20092013) nationally. Human anthrax Cases and deaths were reported in weekly summary report format, not accomplished with line list according to Ethiopian Public Health Emergency Management guideline reporting format. The human anthrax cases annual prevalence was 1.31/100,000 population per year (average midyear population 79234530). All human cases were reported during the specified period on weekly summary format.

The human and animal anthrax cases load was 10 ( 0.01 per 100,000 population) human and 5393 animals) in 2009, 1773 (2.2 per 100,000 population) in 2010, but animal cases $(8187)$ in 2011. In 2012, 1407 (1.7 per 100,000 population and 5639) and in 2013, 1066 (1.3 per 100,000 population) and 4038 both human and animals cases respectively (Figure. 1). 


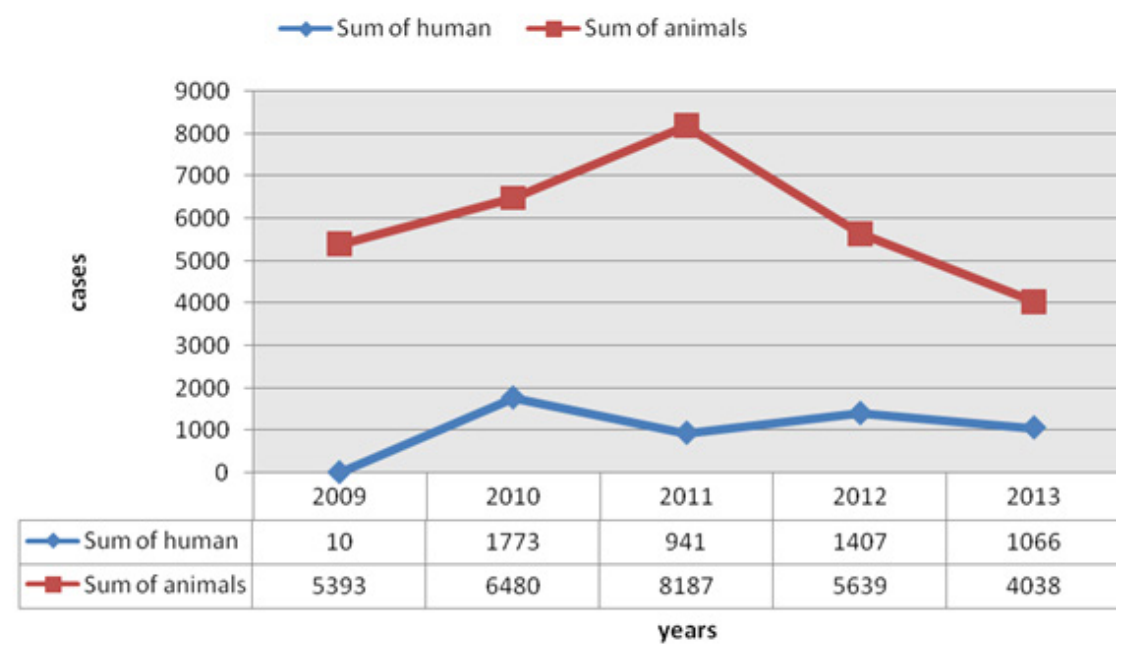

Figure 1: Human and animal anthrax cases by year (2009-2013), Ethiopia 2014

As seen below in Figure 2, the highest number of human case was in May (796 cases) and in animals, it was seen in May and October (3083) and (3205) respectively. Two thousand four hundred fifty four (47.2\%) human cases were reported from February to May; 2149(41.4\%) from June to November; 594(11.4\%) from December to January and regarding animals 10061(37.6\%) cases were reported from March to June; 6111(22.9\%) from September to October; and the load from November to February was 3271(12.2\%). 


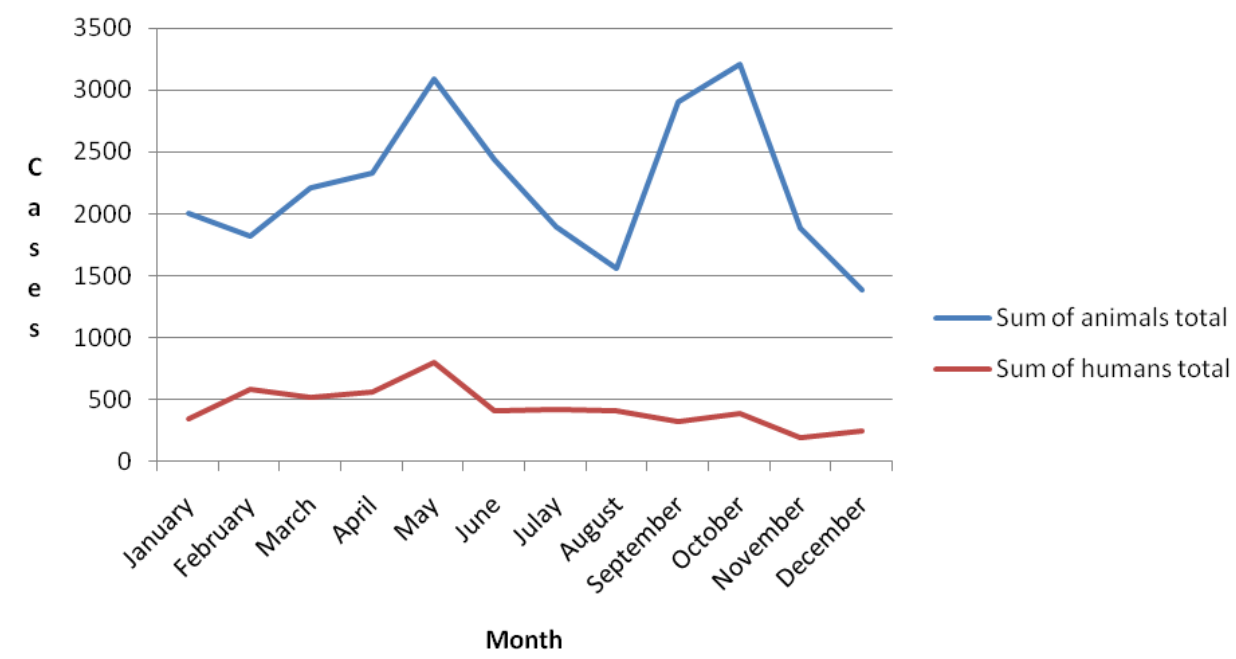

Figure 2: Human and animal anthrax cases by month from 2009-2013, Ethiopia 2014

Table 1: shows that the number of human cases in different regions, range from Zero to 2107. The majority of the cases were reported from Amhara, Tigray, SNNPR, and Oromia. Of which Amhara reported 2107 cases (40.5\%), Tigray1602 (30.8\%), SNNPR 1224(23.7\%) and Oromia 262(5\%), while 1 was observed from Addis Ababa and Gambella and no cases were reported from Afar , Somali, B-Gumuz, Harari, and Diredawa regions. Prevalence of human cases by region was (Tigray: 6.7, Amhara: 2.3, SNNPR: 1.5, Oromia: 0.18, Gambella: 0.06, Addis Ababa: 0.007, and Afar, Somali, B-Gumuz, Harari, Diredawa: 0) per 100,000 population. During 2009-2013, human anthrax case fatality rate (CFR \%) seen (6.1\%) in Oromia, (3.3\%), in SNNP, (0.9\%), in Tigray, (0.7\%), in Amhara.

The Human: Animal anthrax case ratio by region was (Tigray: 2:1, SNNPR: 1:1, Amhara: 1:6, Addis Ababa: 1:12, Oromia: 1:44, and 0:55, 0:216, 0:140 in Afar, B-Gumuz, and Somali regions respectively and no animal case was reported from Dire Dawa and Harari). The data disaggregated in zonal level the ratio 73:1 Bench Maji, 6:1 Central Tigray from SNNPR and Tigray regions respectively. 
Table 1: Human anthrax cases, deaths, incidence and CFR and Animal cases and human to animal anthrax case ratio

\begin{tabular}{|c|c|c|c|c|c|c|}
\hline $\begin{array}{l}\text { Administrative } \\
\text { Region }\end{array}$ & $\begin{array}{c}\text { Human } \\
\text { cases }\end{array}$ & $\begin{array}{c}\text { Human } \\
\text { death }\end{array}$ & $\begin{array}{c}\text { Prevalence/ } \\
100,000 \\
\text { population/ } \\
\text { year }\end{array}$ & CFR (\%) & $\begin{array}{l}\text { Animal } \\
\text { cases }\end{array}$ & $\begin{array}{c}\text { Human/ } \\
\text { Animal } \\
\text { case ratio }\end{array}$ \\
\hline Amhara & 2107 & 15 & 2.3 & $0.7 \%$ & 12577 & $1: 6$ \\
\hline Tigray & 1602 & 14 & 6.7 & $0.9 \%$ & 665 & $2: 1$ \\
\hline SNNPR & 1224 & 41 & 1.5 & $3.3 \%$ & 1333 & $1: 1$ \\
\hline Oromia & 262 & 16 & 0.2 & $6.1 \%$ & 11639 & $1: 44$ \\
\hline Addis Ababa & 1 & 0 & 0.01 & $0.0 \%$ & 12 & $1: 12$ \\
\hline Gambella & 1 & 0 & 0.1 & $0.0 \%$ & 100 & $1: 100$ \\
\hline Afar & 0 & 0 & 0.0 & $0.0 \%$ & 55 & $0: 55$ \\
\hline B. Gumuz & 0 & 0 & 0.0 & $0.0 \%$ & 216 & $0: 216$ \\
\hline Dire Dawa & 0 & 0 & 0.0 & $0.0 \%$ & - & - \\
\hline Harari & 0 & 0 & 0.0 & $0.0 \%$ & - & - \\
\hline Somali & 0 & 0 & 0.0 & $0.0 \%$ & 140 & $0: 140$ \\
\hline Grand total & 5197 & 86 & 1.3 & $1.7 \%$ & 26737 & $1: 5$ \\
\hline
\end{tabular}

\section{Discussion}

This data analysis doesn't include the prevalence of human and animal anthrax between 2009 and 2013in Ethiopia. The prevalence of human anthrax cases in Ethiopia was 1.3/100,000. In addition to that, the fatality of the cases was lower (Case fatality rate 1.7\%) compared to Zambia (WHO, 2008). This might be due to the under reporting of the cases in Ethiopia. As the national Ministry of Health and Ministry of Agriculture surveillance data from 20092013 indicates, more cases of human and animal anthrax were reported from four big regions which have comparatively good surveillance system and trained manpower. The four big regions Amhara, Oromia, SNNPR, and Tigray reported a total of 5195 (99.9\%) human and 26214 (98\%) animal anthrax cases.

The highest human case prevalence was in Tigray followed by Amhara, SNNPR, Oromia, Gambella and Addis Ababa. Only animal cases without human cases were reported from Afar, Somali, and B-Gumuz. This is due to the difference in surveillance system strength. Regions with strong surveillance system reported highest number of both human and animal cases compared to regions with poor surveillance system. Moreover the strength of surveillance system of 
Federal Ministry of Health and Federal Ministry of Agriculture at federal level has significant impact on the result. Like habit of not consuming raw meat may also have an impact not reporting of human case in those regions.

Both suspected human and animal anthrax cases were reported in larger number in the month of May and also larger numbers of animal cases were reported in October. This is dry season, during this time the grass is short and animals are, forced to graze very close to the ground. This increases chances of animals picking up anthrax spores in areas whose soils and pastures are contaminated with the spores (Girum, Shiferaw). Therefore, case of anthrax in animals is very common during this time increasing risk of human anthrax exposure.

In order to combat with the challenges that are ever growing, the way working processes are organized and its capacities should also be changed. Based on this fact the health sector has identified Public Health Emergency Management (PHEM) as one of the core processes to be reengineered in 2009, which could be one of the main reason why out of the total human cases reported between 2009 and 2013 only, 10 (0.2\%) of the cases and Zero case fatality were notified in 2009 .

The human: Animal case ratio from the surveillance data was 1:5. This is opposite to Northern Europe, 1:10 and 10:1 in Africa and Asia (WHO, 2008). This human to animal ratio reflect country's economic condition, quality of surveillance, social traditions and dietary behavior (WHO, 2008). Therefore the result of the five years surveillance data of human and animal anthrax case ratio (1:5) not reflecting both Northern Europe and African situation, this might be the poor quality of surveillance system of the country.

\section{Challenges and limitations}

Anthrax is immediately reportable disease in Ethiopia according to the national Public Health Emergency Management (PHEM) Guideline. Therefore, any human anthrax case and death should be reported either case investigation form or with a line list. All of the cases and deaths were reported in weekly summary report format. This reporting format has no age, sex, urban and rural distribution. Moreover, reported anthrax cases are not classified as suspected, probable and confirmed as per the WHO recommended case definition. The

Ethiop. Vet. J., 2016, 20 (2), 75-85 
cases were not reported as cutaneous, inhalation, and ingestion form of the disease. And there were clear constraints in the data collection and data quality to reach to strong conclusions and recommendations.

\section{Conclusion}

This analysis indicated that anthrax remains to be a major public health problem in Ethiopia. Increasing number of cases and fatalities were reported especially from Amhara, Tigray, SNNPR and Oromia. All regions are not reporting Human suspected anthrax cases with the recommended standard format and the surveillance strength status varies from region to region. There is no emphasis on the implementation of one Health in the country. Control of anthrax depends on the integration of veterinary and human health surveillance and control programmes. Animals should be vaccinated with anthrax vaccine before the season of anthrax. I recommend strong routine crossnotification between the veterinary and human health surveillance systems should be part of any zoonotic disease prevention and control programmes, and close collaboration between the two health sectors is particularly important during epidemiological investigations. All regions and Ministry of Health and Ministry of Agriculture should strength their surveillance system and early preparedness. The case and death should be reported with daily epidemic reporting format or a line list and with case-based immediately and also the case should be reported in specific form of the disease. Continuous data analysis and feedback to all stakeholders should to be conducted on regular bases so as to improve quality of both human and animal surveillance data

\section{Acknowledgements}

I would like to thank Professor Ahmed Ali Addis Ababa University, School of Public Health and Dr.Lucy Boulanger Ethiopia Field Epidemiology Training Program (EFETP) Country Resident Advisor (CDC) for their support and a good advice. I would also like to thank my field supervisor Mr. Abyot Bekele for his leadership and supervision. I also express my gratitude to the Ethiopian Public Health Institute, Public Health Emergency Management Centre and the Ministry of Agriculture, Animal Health Directorate for giving me the five years Anthrax Surveillance Data. 


\section{Reference}

Anonymous, 1998. Anthrax. In: Aiello, S.E., Editor. The Merck veterinary manual. $8^{\text {th }}$ Ed. New Jersey: Merck and co. Inc.432-435

Esser, K., Semagen, K. and Wolde-Yohannes, L., 2003. Medical use and Social status of the soap berry endod (phytolacca dodecandra) in Ethiopia. Ethno. Pharmacol., 85, 269-27.

Hudson, J.A., 2006. Acidophilic and thermophilic Bacillus strains from geothermal heated Antarctic soil. FEMS Microbiol., 60 (3), 279-282.

Hugh-Jones, M.E., 2001. Global anthrax report. J. Appl. Microbial., 87, 189-191.

Inglesby, T.V., Henderson, D.A., Bartlett, J.G., Ascher, M.S., Eitzen, E., Friedlander, A.M., et al., 1999. Anthrax as a biological weapon-medical and public health management. JAMA., 281: 1735-1745.

Inglesby, T.V., Henderson, D.A., Bartlett, J.G., Osterholm, M.T., Parker, G.L., Perl, T.M., et al 2002. Anthrax as a biological weapon, 2002-updated. Recommendations for management, JAMA., 287, 2236-2252.

Lowa State University, 2007. Anthrax Importance: Lowa State University College of Veterinary Medicine.

Ministry of Health., 2000. Health and Health indicators 1992 EC (1999/2000), Addis Ababa, Ministry of Health, Planning and Programming Department.

Ministry of Health., 2000. Health and Health indicators 1992 EC (1999/2000), Addis Ababa, Ministry of Health, Planning and Programming Department.

Ministry of Health., 2001b. Health and Health indicators 1994 EC (2001/2002), Addis Ababa, Ministry of Health, Planning and Programming Department.

Ministry of Health., 2001b. Health and Health indicators 1994 EC (2001/2002), Addis Ababa, Ministry of Health, Planning and Programming Department.

Ministry of Health., 2004. Health and Health indicators 1995 EC (2002/2003), Addis Ababa, Ministry of Health, Planning and Programming Department.

Noah, D.L., Sobel, A.L., Ostroff, S.M. and Kildew, J.A., 1998. Biological warfare training: infectious disease outbreak differentiation criteria. Military Med., 163, 198-201.

Seboxa, T. and Golden, J., 1989. Anthrax in Ethiopia, Trop. Geoger Med., 41, 108-112.

Shiferaw, G., 2004. Anthrax in Wabessa village in Dessie Zuria District of Ethiopia, 23(3), 952-956.

Taylor, L.H., Latham, S. M. and Woolhouse, M. E., 2001. Risk factors for human disease emergence. Philosophical transactions of the Royal Society of London. Series Biological sciences. 356(1411), 983-989.

WHO anthrax guidelines, 2008. Anthrax in humans and Animals, $4^{\text {th }}$ Ed. WHO 2008: 1

Ethiop. Vet. J., 2016, 20 (2), 75-85 